\title{
Interventions to enhance newborn care in North- West Ethiopia: The experiences of Health care professionals
}

Bizuhan Gelaw Birhanu ( $\sim$ bgelaw@gmail.com )

UNICEF

Johanna Mmbabojalwa Mathibe-Neke

University of South Africa

\section{Research Article}

Keywords: Ethiopia, Factors, Newborn, Primary healthcare

Posted Date: January 20th, 2022

DOI: https://doi.org/10.21203/rs.3.rs-1214280/v1

License: (c) (1) This work is licensed under a Creative Commons Attribution 4.0 International License.

Read Full License

Version of Record: A version of this preprint was published at BMC Pregnancy and Childbirth on April 15th, 2022. See the published version at https://doi.org/10.1186/s12884-022-04669-0. 


\section{Abstract \\ Background}

The provision of optimal and quality services during labour, delivery and in the early neonatal period is highly required to accelerate the reduction of neonatal deaths and improve the quality of life of newborns. The availability of competent health professionals and the essential medicines and supplies in the health facilities are compulsory. This study aimed to explore and describe the quality of care provided to newborns in the primary healthcare units.

\section{Methods}

Qualitative exploratory and descriptive design was employed. Focus group discussions were held with 26 participants ( 11 health workers and 15 health extension workers) in three woredas in the West Gojjam zone, Ethiopia. Health workers and health extension workers were purposely selected. Thematic analysis was undertaken.

\section{Results}

The primary healthcare facilities play a major role in the provision of essential services for newborns in the critical periods, including during labor and birth, immediately after birth and in the early postnatal care period. Resuscitation of birth asphyxia, prevention of hypothermia, initiation of breastfeeding, application of tetracycline, vitamin $\mathrm{k}$ injection, weighing babies and chlorhexidine application were identified as immediate essential intervention for the newborns. However, these interventions are hampered by factors such as lack of adequately trained staff \& hands-on skills; weak referral linkage; stock-out of essential medicines and supplies and poor quality for early postnatal care home visits.

\section{Conclusions}

In order to enhance the quality of newborns healthcare provision, the health-systems constraints at health centres and heath posts level should be fixed to provide the required services for newborns. This requires allocation of adequate resources to tackle health facilities readiness related bottlenecks, such as the frequent stock out or lack of essential supplies, equipment, and medicines, lack of proper space for the service provision, not systematic replenishing of the revised job-aids and maintenance of medical equipment, poor infection prevention including water and sanitation in the maternity wards and newborn corners.

\section{Introduction}


During delivery, as such, health professionals should be responsive to safe newborn lives, with the aim of preventing morbidity and mortality [1]. As a result, if the essential quality of services is provided for the mothers and their babies during labour and delivery and in the early postnatal period particularly within the 24 hours, it is expected to contribute to a significant reduction of newborn deaths [2]. Wardlaw et al reported a huge variation on the utilization of services by pregnant women and newborns and quality of services provision by health system to pregnant women and newborns, as per the summary of United Nations Children's Fund (UNICEF) report [3]. Furthermore, UNICEF 2014 highlighted that, quality of care is not offered for the newborns and mothers who are already visiting the health system. And that many mothers and newborns miss out key interventions that can save their lives [2]. The assessment done on newborn care in Indonesia, Lao People's Democratic Republic and the Philippines [4] reported that within primary healthcare and referral level health facilities, newborn care services provision is found to be poor in quality as also compounded by incompetency of health professionals as also supported by Duysburg, et al,[4].

As stated by Kruk, et al 2018, and Lawn et al 2014, most newborns lives can be saved if the health facilities provides high-quality care by ensuring the availability of essential medicines and commodities, compliance with evidence-based clinical interventions and practices, adequate infrastructure and supplies to ensure infection prevention and control, competent, motivated staff and solid documentation and use of information [1, 5]. According to Knippenberg, et al, essential interventions contributing for the reduction of neonatal morality are not dependant on technologies or supplies; rather on the adequate skills that the health care providers should be competent on at all levels [6]. According to every newborn action plan [7] each country is expected to reduce their respective neonatal deaths up to the level of ten or less per 1,000 live births by 2030 .

\section{Objective}

This study aimed to explore and describe the quality of care offered to newborns by frontline healthcare providers in primary healthcare units in the North-West of Ethiopia.

\section{Methods}

\section{The research approach and design}

Qualitative exploratory and descriptive design was employed [8, 9]. Focus group discussion (FGD) was selected as one of the techniques that produce data in collective space in such kinds of expert groups [10, $11]$.

\section{Population of the study}

Three woredas (districts) namely Bahir Dar Zuria, Mecha and South Achefer in the West Gojjam zone, North-West of Ethiopia were selected purposely for the study. West Gojjam is one of the 11 administration zones in the Amhara regional state and consisting of fifteen woredas. In these selected woredas, three 
health centres (HCs) and four health posts (HPs) were selected purposely. The targeted population was health workers (HWs) in HCs who were working in maternity ward (delivery and early post-natal) and under-five clinic and all health extension workers (HEWs) who were working in the HPs in selected heath facilities.

\section{Data collection}

Written consent was obtained from each participant including audio recording of their responses. Participation was voluntary. The focus group discussions (FGDs) were held separately for the HCs and HPs staff. Twenty-six participants were interviewed through FGD in seven rounds of discussions. Health workers and HEWs who were working in the maternity wards and under-five clinics participated in the FGD's. The principal investigator specified the objectives and information needs of the FGD and took the responsibility of moderation to facilitate the discussion, probing, and encouraging all the members to participate. The assistant moderator was taking notes and the discussions were held at their respective private room in the health facilities. In addition to note taking, the discussions were recorded with audiotape. After each session of FGDs, the audio-recorded information and note recorded were checked for their consistency.

\section{Data analysis}

Data analysis was initiated within the data collection process. All audiotape records were transcribed into Amharic and the 44 pages' Amharic transcription was directly translated into English by linguistic expert. Thematic analysis was employed with different stages, familiarizing the data, generating initial codes, searching for themes, reviewing the themes, defining and naming the themes and producing the report $[12,13]$. Overall, the qualitative analysis was done manually.

\section{Ethics approval and consent to participate}

This study was conducted under the ethical principles of the Declaration of Helsinki. Ethical clearance was obtained from University of South Africa (UNISA) Research and Ethics Committee (Ref no: HSHDC/489/2015). The Amhara regional health bureau and West Gojjam Zone provided permission to conduct the study. Participants privacy and the confidentiality of information given were maintained throughout the study. Information on the study's purpose, procedures, risks, burdens, and benefits as well as confidentiality was provided. Written informed consent was obtained from each study participants before the discussion and confidentiality of information was maintained throughout the study. Field notes and tape-recorded voices were kept properly and the health facilities and health professionals' unique personal identification was anonymized in the report or shared [14].

\section{Trustworthiness}

The FGDs interview guide was pre-tested to ascertain the credibility. Likewise, to ensure dependability, the audio data and transcribed data both in English and Amharic kept for further verification. The data collection process in the field and data analysis procedure was documented. In addition, FGDs 
participants' voice and speech were quoted and included as part of the report as a strategy of ensuring conformability. Transferability was confirmed by providing a thorough explanation of the methods of the data collection and its tool, the types of healthcare providers, the steps and the procedures applied for the analysis and presentation to support the major quantitative findings $[15,16]$.

\section{Results}

Amongst the four FGDs, three of them were held with health providers who were working in the respective $\mathrm{HCs}$; and the rest of the four discussions were conducted with HEWs at HPs level. Participants in this FGDs were identified and reported as per their group and participant number given during each FGDs (Tables 1 and 2). The FGDs key finding is presented and discussed based on the identified major themes and sub-themes Due to the level of care difference between the HCs and HPs, the emerged themes are reported discretely.

Table 1: FGD participants among HWs in HCs in West Gojjam Zone, Ethiopia.

\begin{tabular}{llll}
$\begin{array}{l}\text { Focus } \\
\text { group }\end{array}$ & $\begin{array}{l}\text { Number of } \\
\text { participants }\end{array}$ & $\begin{array}{l}\text { Identification of participants in } \\
\text { their group }\end{array}$ & $\begin{array}{l}\text { Unique identification number for } \\
\text { each participant }\end{array}$ \\
\hline Group 1 & 4 & Group1- Participant 1-4 & G1/P1-4 \\
\hline Group 2 & 3 & Group2-Participant 1-3 & G2/P1-3 \\
\hline Group 4 & 4 & Group 4- Participant 1-4 & G4/P1-4
\end{tabular}

Total 11

Table 2: FGD participants among HEWs in HPs in West Gojjam Zone, Ethiopia.

\begin{tabular}{llll}
$\begin{array}{l}\text { Focus } \\
\text { group }\end{array}$ & $\begin{array}{l}\text { Number of } \\
\text { participants }\end{array}$ & $\begin{array}{l}\text { Identification of participants in } \\
\text { their group }\end{array}$ & $\begin{array}{l}\text { Unique identification number for } \\
\text { each participant }\end{array}$ \\
\hline Group 3 & 6 & Group 3-Participant 1-6 & G3/P1-6 \\
\hline Group 5 & 3 & Group 5- Participant 1-3 & G5/P1-3 \\
\hline Group 6 & 3 & Group 6- Participant 1-3 & G6/1-3 \\
\hline Group 7 & 3 & Group 7-Participant 1-3 & G7/P1-3 \\
\hline Total & 15 & &
\end{tabular}

\section{Interventions and platforms for newborn care services}




\section{Experiences of the HCs on neonatal health care services}

The immediate and essential newborn care services are provided in HCs for the newborn such as resuscitation if she/he develops birth asphyxia, initiated breastfeeding, application of tetracycline in the eyes, vitamin $\mathrm{k}$ injection, weighing and chlorhexidine application in the cord (Table 3).

Table 3: Major themes and sub-themes of HC staff participants' responses in West Gojjam Zone, Ethiopia.

\section{Major themes}

Experiences of the HCs on neonatal health care services

\section{Sub-themes}

Chlorhexidine jel (4\%) application for cord care

Management of preterm labour

Management of birth asphyxia

Kangaroo mother care

Early PNC for the mothers and newborns

Quality of neonatal healthcare services

Availability of material resources

Competency of HCs personnel

Referral linkage
Linkage for early PNC home visit

\section{Chlorhexidine (4\%) application for cord care}

In line with the experience in the use of chlorhexidine (4\%), "Yimserach jel" the local brand name, was discussed with HWs. Thus, "Yimserach jel" was available in the HCs. As per the ministry of health recommendation, the application has started in $\mathrm{HC}$ after delivery and the mother take away the remaining to apply at home.

G4/P1: "It is available. We [HC staffs] apply once and demonstrate to them then they apply the remaining 6 days."

\section{Management of preterm labour}

All the HCs discussants agreed that, they are not equipped to provide intramuscular dexamethasone or other corticosteroids for pregnant woman at risk of preterm birth; and guideline is not available in their respective health facilities. Consequently, if the HCs are confronted with preterm labour, referring the pregnant woman to the higher-level facility is the usual practice. 
G2/P3: "No service [for preterm labour]. There is some concept during in some training, but not practically available. And dexamethasone service is not available. We refer to higher facility if preterm labour occurred."

G4/P1: "Management of preterm labour guideline is not available, we [HC staff] haven't trained yet."

\section{Management of birth asphyxia}

The HCs group discussion participants revealed that they have relatively adequate knowledge and received training on the management of birth asphyxia to save the lives of newborns immediately after birth. However, most of the HCs staff complained that the narrow space in the delivery room; shortage of supplies for resuscitation; misappropriate use of supplies; and limited competency since the HCs staffs are not often practicing the skills mainly due to the limited number of case were some of the factors mentioned by the HCs staff which was affecting the resuscitation process.

G2/P3: "...shortage of material supply, misappropriate use of some plastic materials, technical problems... poor skills of the HWs, practical training should be mandatory."

G4/P1: "The class is very small to resuscitate the baby and no table for resuscitation...there is no resuscitation section/room... the case [newborn with birth asphyxia] is not present in the previous 6 months."

\section{Kangaroo mother care (KMC)}

In the discussion with the HCs staff, often KMC was only initiated in cases of referral of very /low preterm or low birth weight newborns to hospitals. Otherwise, cases were not admitted at HCs for KMC services. In addition, initiating $\mathrm{KMC}$ at $\mathrm{HC}$ and linking to the HP was not a common practice as well. Most of the $\mathrm{HC}$ staffs confirmed that, the HCs are not ready to provide the required KMC services since the existing rooms are already overstretched, or lack of room and poorly equipped with beds and the required supplies.

G4/P1: "We [HC staff] initiate KMC and then refer them to the higher facility [hospitals]. It is advantageous if KMC section has one room independently ... there is no defined room for KMC service. There is no on-job training and no referee guidelines to practice KMC."

\section{Early PNC for the mothers and newborns}

All the $\mathrm{HC}$ discussion participants agreed that, they were experiencing early discharge than the recommendations to stay the mother and baby for the 24 hours after delivery in their respective health facilities. Among the frequently mentioned reasons for early discharge were lack of dedicated space and beds for PNC in their respective HCs. In addition, once the mother gave birth the family members and the accompanies consider that there is no problem after birth and they want to go and practice some traditional celebration at home with their families and neighbours. 
G2/P3: "Early discharge takes place because of absence of enough space or room ... we [HC staffs] discharge them within six hours after birth. There is also understanding problem among the community, they think that as if there is no problem after mothers give birth, and they ask immediately for discharge after birth".

\section{Quality of neonatal healthcare service provision}

Regarding the quality of the neonatal healthcare provision at $\mathrm{HC}$ level, due to suboptimal availability of trained human resources, material resources and essential medicines and supplies, most of the HC participants agreed that the service provided for the newborns is not as high as expected quality standards. Nevertheless, some HC participants argue that the HCs are trying their best to provide the quality of health care services for the newborns.

\section{Availability of material resources}

The participants agreed that, even though there was a positive trend, sometimes, health facilities were still experiencing stock-out of essential supplies, medicine and job-aids. Adequate or dedicated space for $\mathrm{KMC}$ and early PNC was not available in the HCs.

G2/P2: "Yes, adequate medicine and job-aids are present, only last time there was shortage. Within 2 years of my experience in this HC there was shortage of Ampicillin for some three months."

\section{Competency of HCs personnel}

HCs staffs claimed that the quality of neonatal health care services at $\mathrm{HC}$ level was sub-optimal and the consistency of the services was not always maintained at all the times. Lack of trained human resources, newborn health reference guidelines to up-to-date the knowledge and practice, and motivation were some key factors affecting the quality of service provision.

G1/P2: "There is shortage of trained staff, we can't conclude there is quality service delivery."

\section{Referral linkage}

Though the referral link not strong enough, each level of care across the primary healthcare system is also connected to referral linkage.

\section{Linkage for early PNC home visit}

There was no a strong mechanism established at HCs level to inform the HEWs at HPs level about the birth occurring at HCs level for their early home visits for PNC. In fact, some of the HCs staffs were sending a green colour notification card to the HEWs at HPs to continue the PNC and other essential services for the newborn and the mother. 
G2/P3: "There is a problem of reaching to HEWs... some husbands take the green notification card [from the HC during discharge] and ignore to give to HEWs. The card contains time of birth, infants' weight. HEWs can't get this information if the card did not reach them. When we ask HEWs to check whether they got those cards they replied that as they do not have any information, and we give them information again for the 2nd time."

\section{Experiences of the HPs on neonatal health care services}

HEWs' who are working in the HPs, the first level of care in the Ethiopian health system. HEWs participants revealed that, most of the community based newborn care services initiated at HP such ANC, facilitating health facility delivery and early PNC for essential newborn care (Table 4).

Table 4: Major themes and sub-themes of HEWs participants' responses in West Gojjam Zone, Ethiopia.

\section{Major themes}

Experiences of the HPs on neonatal health care services

\section{Sub-themes}

Neonatal intervention across the continuum of care

Facilitating transportation services for pregnant women

Early PNC home visits

Counseling on thermal care and breastfeeding

Birth notification

Chlorhexidine jel (4\%) application

Detection of preterm or low birth weight babies

\section{Antenatal care screening}

HEWs confirmed that they were mainly engaged in the identification of pregnant women in their respective community, followed by provision of the antenatal care (ANC) services at HP level. They are also referring the pregnant women to the nearby HCs for the additional ANC services.

G7/P2: "We [HEWs] tell her danger signs may occur during pregnancy such as: things related to anaemia and blood pressure, we counsel them to get follow-up service and refer them if the problem is somewhat complex..., because there is a pregnant woman waiting home in the $\mathrm{HC}$, we also advise her to stay there when the expectant mother enter her 9th month".

Facilitating transportation services for pregnant women 
Most of the HEWs agreed that they were trying their best in connecting the pregnant women as soon as labour is initiated or anticipated to get the ambulance transportation services from their home to $\mathrm{HC}$ or hospital to facilitate professional assisted delivery. Because of this facilitation, HEWs believe that the coverage of delivery in the HCs or hospitals has significantly increased when it compared with the previous years.

G3/P1: "During the pregnant women conference we give them [pregnant women] the ambulances phone address to call when labour occurred."

\section{Early PNC home visits}

The experience on provision of early PNC was varied among the HEWs participants. Some of the homes either did not receive or received a delayed PNC visit by HEWs; even some of the women didn't get the PNC visit at all. Majority of newborns will not get the key lifesaving interventions and essential newborns care in the recommended period by HEWs, particularly for those mothers who gave birth at home and early discharged from the health facilities.

G7/P3: "There were 109 births and we made home visit for PNC between 3-7 days, there were mothers who didn't get the home visit for PNC."

G6/P2: "When we are going for other duties [in the village] we don't carry nothing because of our attention is on the other job."

The study also explored the existing birth notification or communication system in placed to carry-out the home visits for PNC by HEWs. However, some common mechanisms exist to notify births, but there are no a clear and standard pathway for timely notification of births. Occasionally, HEWs were getting report or information from the community health works (Women Development Armies), and rarely they were receiving a message from the delivered mother by themselves like 'come and see me'. Overall, the timeline range receiving notification by HEWs is about 2-7 days from the onset of delivery.

G7/P2: "We know most of pregnant women are giving birth at health centre; the midwife writes a letter for us. There is a paper the mother supposed to gives to us. ...but sometimes we get the notification letter at 45 days when they come for vaccination."

\section{Health information on thermal care and breastfeeding}

During home visits, HEWs agreed that they are providing counselling services to delay bathing of the neonate, assessing the feeding condition of the neonate following with counselling of the mother especially for exclusive breastfeeding up to 6 months; and reminding the schedule of the immunization at 45 days of birth.

G7/P3: "We [HEWs] check also her [mother] feeding situation, breastfeeding status of the neonate." 
In the discussion with the HEWs participants' chlorhexidine (4\%), "Yimserach jel", was lacking in HPs despite the current policy does not allow HEWs to attend delivery at HP level. However, still a significant number of mothers gave birth at home where infection prevention is a concern. Thus, the role of HEWs are limited to checking the application of "Yimserach jel" during home visits for those mothers who gave birth at $\mathrm{HC}$ or hospital and if they received the jel.

G3/P1: "They gave us [HEWs] sample but not available now. It is available at HC. Many mothers told me that they took it from HC and applied to their newborn' umbilicus."

\section{Detection of preterm or low birth weight babies}

In addition, most of the time HEWs were not carrying the required tools for PNC home visits such as weight measurement scale, thermometer and timer. As a result, the weight of the newborns is not taken and assessed for birth weight especially for newborns at home delivery.

G3/P4: "All of us are not practicing checking their weight and count breathing after we make follow-up of infants, but only registering them...."

\section{Discussion}

Immediate drying and additional stimulation or resuscitation for birth asphyxia, prevention of hypothermia including skin-to-skin contact in the first hour of life, late cord clamping after 1-3 minutes, initiation of breastfeeding, application of tetracycline, vitamin k injection, weighing the babies, and chlorhexidine application are the immediate essential newborn intervention which are provided at the health centres. In addition, during early postnatal home visits, prevention of hypothermia including delay bathing of the newborn, optimal breastfeeding, weighing the babies and chlorhexidine application were often recommended to be practiced by HEWs. This study found that, as per the perception of the frontline healthcare providers, the quality of care provided to newborns in the primary healthcare units was affected by the non-availability of material resources and limited skill set of the HCs staff. The findings of this study is supported by Islam et al 2015 [17] on the study conducted to understand the views of healthcare professionals and their patients on the quality of care provided for newborns and their mothers in healthcare facilities in Bangladesh. It highlighted that inadequate healthcare providers and supplies; non-adherence to job-aids or service delivery standards; staff not adequately trained; and inadequate mentorship or supportive supervision from hospital clinicians were some of the bottlenecks that were affecting the quality of healthcare provision for newborns and their mothers.

Regardless of the World Health Organization (WHO) and national recommendations [18-20] on the timing of discharge, at least 24 hours after birth from the health facility for an uncomplicated vaginal birth; this study found that, often, due to limited space and preference of women family to go home immediately after delivery, HCs were not retaining mothers and newborns for PNC at least 24 hours after delivery. This was a great missed opportunity for the mother and the newborn to receive the early PNC in the critical periods, since majority of neonatal mortality occurs within the first 48 hours after birth. Similarly, as 
stated by Tiruneh, et al 2020, on the determinants of postnatal care utilization in Ethiopia, health servicerelated factors were reported as a significant determinants for use of postnatal care [21]. As continuum of care, the Ministry of Health Ethiopia guided the HEWs should carry-out early postnatal home visits [22]; however, the coverage of early PNC home visits is very low and the quality of visits was poor or suboptimal. This is in line with the study conducted regarding postnatal home visitation by McPherson and Hodgins 2018 in the 12 countries, the provision of postnatal care within 48 hours of after birth following home birth is below 10 percent in most of the countries [23]. Another qualitative study done on the early postnatal home visits in two regions of Ethiopia, reported that, some inaccessible areas did not receive visits [24].

As stated by American Academy of Pediatrics 2011, a newborn baby who fails to breath at birth, shall be quickly dried, stimulated and resuscitated with bag and mask, to help the baby to breathe in one minute, "golden minute". Furthermore, ventilation with bag and mask is the most important and effective way to open the lungs of the baby with air. Delay in ventilation may result in preventable death or brain damage [25]. In this study the HWs believed that they have basic knowledge and skills to manage birth asphyxia, but they considered that the resuscitation process is impacted by lack of adequate space, shortage and misappropriate use of supplies, and they were not confident enough on their skill set due to the limited exposure to the cases of birth asphyxia. In line with this, the study done in Tanzania by Haug et al 2020 on the video analysis of newborn resuscitations after simulation-based helping babies breathe training [26] noted that the actual newborn resuscitation practice deviated from the recommendation such as ventilation was delayed and frequently interrupted. In another qualitative study in Tanzania [27] on factors affecting effective ventilation during newborn resuscitation, the readiness's of the ventilation supplies in delivery room, working as a team and repeated training to improve the competency skills found to be the trigger factors for the health care providers to provide and practice of the immediate newborn care practice .

It is an important intervention that is aiming to ensure the thermal care for both preterm and low birthweight newborns. KMC should be initiated in the health facilities and the newborn should stay in the KMC for 24 hours [20, 28]. However, in this study, the HCs were mainly exercising KMC services as prereferral intervention to hospital or due to the poor quality and delayed PNC home visits, HPs staff were not detecting the preterm or low birth weight babies at community level. Similarly, as per a systematic review to assess the bottlenecks and facilitators on the implementation of KMC services across in the health system; both healthcare workers and their health facilities face unique barriers to implementing KMC [29].

In Ethiopian context, regardless of the place of delivery, a-daily chlorhexidine (4\%) application for one week is recommended [22] . The application of chlorhexidine (4\%), "Yimserach jel" on the umbilical cord stump of the newborn initiated immediately after birth and daily application for the following six days at home. In this study, the response of the HCs staff was consistent with the national recommendation. Chlorhexidine was included as one of the components in the community based newborn care implemented by HEWs [30], however, this study found that, in the early phases of "Yimserach jel" 
introduction, it was available at HP level, later, often "Yimserach jel" was not refilled and available at HPs level. Consequently, mothers who gave birth at home their newborns won't get Yimserach jel" from the HEWs during their home visits. The study done in Ethiopia also stated that even though the "Yimserach jel" was manufactured locally, its availability was limited outside of facilities [30].

This study also found that, the HCs were not equipped with regard to the required competency and required essential medicines, supplies and equipment to manage preterm labour. As the result, the health centres role limited to rereferral of expected cases to hospital. At the current standards and health centre readiness limitation, participants could not manage women presenting with preterm labour as outlined by WHO [19].

\section{Recommendations}

- The primary healthcare facilities play a major role in the provision of essential services for newborns in the critical periods, including during labor and birth, immediately after birth and in the early postnatal care period. This requires allocation of adequate resources to tackle health facilities readiness related bottlenecks, such as the frequent stock out or lack of essential supplies, equipment, and medicines, lack of proper space for the service provision, not systematic replenishing of the revised job-aids and maintenance of medical equipment, poor infection prevention including water and sanitation in the maternity wards and newborn corners.

- The Ministry of health in collaboration with developing partners, professional associations, and local universities, should organize the low-dose high frequency onsite hands-on training for the clinicians to improve their skills to provide the quality of newborn care services, at least every year.

- The training needs to be augmented by clinical mentorship or a systematic programme specific supportive supervision visits to the respective healthcare facilities. This will help to build clinicians and healthcare providers confidence and improve their competency on the quality of newborn healthcare services provision and ensure adherence on the use of job-aids and service delivery standards.

- The local authorities and the PHCUs shall provide attention and focus to improving the quality of newborn health services during labour, delivery and in the early neonatal period.

- Improving the coverage and quality of PNC home visits at the community level should be the major tasks by HEWs. It should be a targeted visit with adequate preparation including essential checklist and supplies; so that, the HEWs can provide the routine newborn care and early detect the premature, low birth weight or babies' signs of infection.

\section{Conclusion}

The quality of newborn healthcare provision in North-West Ethiopia should be enhanced to improve the quality of life and reduce neonatal mortality and morbidity. The health systems related constraints at 
health centres and health posts levels should be fixed to provide the required service for newborns.

\section{Abbreviations}

FDG; Focus Group Discussion; HCs; Health Centres; HEWs; Health Extesion Workers; HWs; Health Workers; KMC; Kangaroo Mother Care; PHCUs; Primary Healthcare Units; PNC; Postnatal Care.

\section{Declarations}

\section{Ethics approval and consent to participate}

This study was conducted under the ethical principles of the Declaration of Helsinki. Ethical clearance was obtained from University of South Africa (UNISA) Research and Ethics Committee (Ref no: HSHDC/489/2015). The Amhara regional health bureau and West Gojjam Zone provided permission to conduct the study. Participants privacy and the confidentiality of information given were maintained throughout the study. Information on the study's purpose, procedures, risks, burdens, and benefits as well as confidentiality was provided. Written informed consent was obtained from each study participants before the discussion and confidentiality of information was maintained throughout the study. Field notes and tape-recorded voices were kept properly and the health facilities and health professionals' unique personal identification was anonymized in the report or shared.

\section{Consent for publication}

Not applicable.

\section{Availability of data and materials}

It can be obtained from the corresponding author.

\section{Competing interests}

The authors declare that they have no competing interests.

\section{Funding}

The authors declare that there is no funding source.

\section{Authors' contributions}

The authors declare their responsibility for the following tasks (according to their initials). Bizuhan Gelaw Birhanu (BGB), Johanna Mmabojalwa Mathibe-Neke (JMM): BGB has designed the study and involved in the data collection, supervision, data processing \& analyzing; and drafting the manuscript. JMM has reviewed the research design \& data collection tools and supported the interpretation and analysis, as 
well reviewing the manuscript. All the authors have critically reviewed and approved the manuscript. The research was previously formed part of a PhD at the University of South Africa.

\section{Acknowledgements}

The authors would like to thank UNISA for approving the ethical clearance. In addition, we would like to thank data collectors and study participants.

\section{Authors' information}

\section{Affiliations}

Community Newborn and Child Health Specialist, Health Section, UNICEF Ethiopia Country Office, Addis Ababa, Ethiopia

Bizuhan Gelaw Birhanu, ORCID: https://orcid.org/0000-0002-2297-0011

Professor, Department of Health Studies, College of Human Sciences, University of South Africa, Pretoria, South Africa

Johanna Mmabojalwa Mathibe-Neke, ORCID : https://orcid.org/0000-0002-5811-8680

Corresponding author

Correspondence to Bizuhan Gelaw Birhanu, email: bgelaw@gmail.com

[1] Community Newborn and Child Health Specialist, Health Section, UNICEF Ethiopia Country Office, Addis Ababa, Ethiopia

2 Professor, Department of Health Studies, College of Human Sciences, University of South Africa, Pretoria, South Africa

*Correspondence: bgelaw@gmail.com

\section{References}

1. Lawn JE, Blencowe H, Oza S, You D, Lee AC, Waiswa P, Lalli M, Bhutta Z, Barros AJ, Christian P et al: Every Newborn: progress, priorities, and potential beyond survival. Lancet 2014, 384(9938):189-205.

2. UNICEF: Committing to Child Survival:A Promise Renewed,Progress Report 2014. 2014.

3. Wardlaw T, You D, Hug L, Amouzou A, Newby H: UNICEF Report: enormous progress in child survival but greater focus on newborns urgently needed. Reprod Health 2014, 11(1):82.

4. Duysburgh E, Kerstens B, Diaz M, Fardhdiani V, Reyes KA, Phommachanh K, Temmerman M, Rodriques B, Zaka N: Newborn care in Indonesia, Lao People's Democratic Republic and the Philippines: a comprehensive needs assessment. BMC Pediatr 2014, 14(1):46. 
5. Kruk ME, Gage AD, Arsenault C, Jordan K, Leslie HH, Roder-DeWan S, Adeyi O, Barker P, Daelmans B, Doubova SV et al: High-quality health systems in the Sustainable Development Goals era: time for a revolution. Lancet Glob Health 2018, 6(11):e1196-e1252.

6. Knippenberg R, Lawn JE, Darmstadt GL, Begkoyian G, Fogstad H, Walelign N, Paul VK, Lancet Neonatal Survival Steering T: Systematic scaling up of neonatal care in countries. Lancet 2005, 365(9464):1087-1098.

7. WHO, UNICEF: Every newborn: an action plan to end preventable deaths. Geneva: World Health Organization 2014.

8. Hunter D, McCallum J, Howes D: Defining Exploratory-Descriptive Qualitative (EDQ) research and considering its application to healthcare. Journal of Nursing and Health Care 2019.

9. Kim H, Sefcik JS, Bradway C: Characteristics of Qualitative Descriptive Studies: A Systematic Review. Res Nurs Health 2017, 40(1):23-42.

10. Kinalski DD, Paula CC, Padoin SM, Neves ET, Kleinubing RE, Cortes LF: Focus group on qualitative research: experience report. Rev Bras Enferm 2017, 70(2):424-429.

11. Escalada M, Heong K: Focus group discussion.Accessed 13 April 2021 (http://www.knowledgebank.irri.org/capdev/images/stories/tools/Tools-Focus-groupdiscussion.pdf). In.: Retrieved from ricehoppers. net: http://ricehoppers. net/wp-content/uploads ...

12. Braun V, Clarke V: Thematic analysis. 2012.

13. Castleberry A, Nolen A: Thematic analysis of qualitative research data: Is it as easy as it sounds? Curr Pharm Teach Learn 2018, 10(6):807-815.

14. Arifin SRM: Ethical considerations in qualitative study. Accessed 9 April 2021 (https://journals.iium. edu.my/ijcs/index.php/ijcs/article/view/82/27). International Journal of Care Scholars 2018, 1(2):30-33.

15. Polit DF, Beck CT: Generalization in quantitative and qualitative research: myths and strategies. Int $J$ Nurs Stud 2010, 47(11):1451-1458.

16. Gunawan J: Ensuring Trustworthiness in Qualitative Research. Belitung Nursing Journal 2015, 1(1):10-11.

17. Islam F, Rahman A, Halim A, Eriksson C, Rahman F, Dalal K: Perceptions of health care providers and patients on quality of care in maternal and neonatal health in fourteen Bangladesh government healthcare facilities: a mixed-method study. BMC Health Serv Res 2015, 15(1):237.

18. FMOH: National strategy for newborn and child survival in Ethiopia 2015/16-2019/20. Accessed 13 April 2021 (https://www.healthynewbornnetwork.org/resource/national-strategy-newborn-childsurvival-ethiopia/\#). 2015.

19. WHO: WHO recommendations on maternal health: guidelines approved by the WHO Guidelines Review Committee (accessed 4 April 2021) https://www. who.int/publications/i/item/WHO-MCA17.10. 2017. 
20. WHO: WHO recommendations on newborn health: guidelines approved by the WHO Guidelines Review Committee. In.: World Health Organization; 2017.

21. Tiruneh GT, Worku A, Berhane Y, Betemariam W, Demissie M: Determinants of postnatal care utilization in Ethiopia: a multilevel analysis. BMC Pregnancy Childbirth 2020, 20(1):549.

22. Federal Ministry of Health Ethiopia: Community based newborn care implementation plan. 2013.

23. McPherson R, Hodgins S: Postnatal home visitation: Lessons from country programs operating at scale. J Glob Health 2018, 8(1):010422.

24. Amare Y, Scheelbeek P, Schellenberg J, Berhanu D, Hill Z: Early postnatal home visits: a qualitative study of barriers and facilitators to achieving high coverage. BMC Public Health 2018, 18(1):1074.

25. American Academy of Pediatrics(AAP): Guide for implementation of helping babies breathe: Strengthening neonatal resuscitation in sustainable programs of essential newborn care. Accessed 4 April 2021 (https://www.aap.org/en-us/Documents/hbs_implementationguide_english.pdf). 2011.

26. Haug IA, Holte K, Chang CL, Purington C, Eilevstjønn J, Yeconia A, Kidanto H, Ersdal HL: Video Analysis of Newborn Resuscitations After Simulation-Based Helping Babies Breathe Training. Clinical Simulation in Nursing 2020, 44:68-78.

27. Moshiro R, Ersdal HL, Mdoe P, Kidanto $H L$, Mbekenga $C$ : Factors affecting effective ventilation during newborn resuscitation: a qualitative study among midwives in rural Tanzania. Glob Health Action 2018, 11(1):1423862.

28. FMOH: Pediatric hospital care: Ethiopia pocket book: Guidelines for the management of common illnesses in hospitals. 2nd edition. 2016.

29. Chan G, Bergelson I, Smith ER, Skotnes T, Wall S: Barriers and enablers of kangaroo mother care implementation from a health systems perspective: a systematic review. Health Policy Plan 2017, 32(10):1466-1475.

30. Tadesse Y, Abdella YM, Tadesse Y, Mathewos B, Kumar S, Teferi E, Bekele A, Gobezayehu AG, Wall S: Integrating Chlorhexidine for Cord Care into Community Based Newborn Care in Ethiopia. Ethiopian Medical Journal 2019(3). 